Published in final edited form as:

Invest New Drugs. 2012 June ; 30(3): 1175-1183. doi:10.1007/s10637-011-9658-9.

\title{
A randomized phase II of gemcitabine and sorafenib versus sorafenib alone in patients with metastatic pancreatic cancer
}

\author{
A. B. El-Khoueiry, \\ Division of Medical Oncology, Keck School of Medicine, Norris Comprehensive Cancer Center, \\ University of Southern California, 1441 Eastlake Ave, Suite 3440, Los Angeles, CA 90033, USA \\ R. K. Ramanathan, \\ University of Pittsburgh Cancer Institute, Pittsburgh, PA, USA \\ D. Y. Yang, \\ Department of Preventive Medicine, Keck School of Medicine, Norris Comprehensive Cancer \\ Center, University of Southern California, Los Angeles, CA, USA
}

\section{W. Zhang,}

Division of Medical Oncology, Keck School of Medicine, Norris Comprehensive Cancer Center, University of Southern California, 1441 Eastlake Ave, Suite 3440, Los Angeles, CA 90033, USA

\section{S. Shibata,}

City of Hope Cancer Center, Medical Oncology, Duarte, CA, USA

\section{J. J. Wright,}

Investigational Drug Branch, Cancer Therapy Evaluation Program, National Cancer Institute, Bethesda, MA, USA

D. Gandara, and

UC Davis Cancer Center, Internal Medicine-Hematology/Oncology, Sacramento, CA, USA

\section{H. J. Lenz}

Division of Medical Oncology, Keck School of Medicine, Norris Comprehensive Cancer Center, University of Southern California, 1441 Eastlake Ave, Suite 3440, Los Angeles, CA 90033, USA

Department of Preventive Medicine, Keck School of Medicine, Norris Comprehensive Cancer Center, University of Southern California, Los Angeles, CA, USA

A. B. El-Khoueiry: elkhouei@usc.edu

\section{Summary}

Purpose-Patients with metastatic pancreatic cancer have limited therapeutic options. The role of the Ras-Raf-MAPK pathway and of vascular endothelial growth factor in pancreatic carcinogenesis provided the rational to evaluate the efficacy of sorafenib with or without gemcitabine in a randomized phase II study.

Methods-Patients with metastatic pancreatic cancer were randomized to sorafenib alone (arm A) or sorafenib with gemcitabine (arm B).

\footnotetext{
(C) Springer Science+Business Media, LLC 2011

Correspondence to: A. B. El-Khoueiry, elkhouei@usc.edu.

Disclosures Dr. Heinz-Josef Lenz receives clinical trial funding from Bayer Phrmaceuticals. Dr. Anthony El-Khoueiry is on the speaker's bureau for Bayer Pharmaceuticals. No other authors have conflicts of interest.
} 
Results-Arm A was closed to accrual at interim analysis due to the lack of objective response. Median PFS and OS were 2.3 and 4.3 months respectively. There was one partial response among the 37 patients in arm B. Median PFS and OS were 2.9 and 6.5 months respectively. There were more grade 3 and 4 toxicities in arm B with the most common being neutropenia (17\%), thrombocytopenia (8\%), alkaline phosphatase elevation (14\%), venous thromboembolism (8\%), diarrhea, hypokalemia and ALT elevation (5\%) each. Several associations were noted between single nucleotide polymorphisms in ribonucleotide reductase, Cox-2, vascular endothelial growth factor and survival in patients treated with gemcitabine and sorafenib.

Conclusions-Neither sorafenib alone or sorafenib in combination with gemcitabine manifested promising activity in metastatic pancreatic cancer.

\section{Keywords}

Pancreatic cancer; Sorafenib; Gemcitabine; Ribonulceotide reductase

\section{Introduction}

Pancreatic cancer represents a serious health challenge with an estimated 43,410 new cases and 36,800 deaths in 2010 in the United States [1]. The high mortality rate is a result of multiple factors including the biology of the cancer and the fact that the majority of patients present with advanced or unresectable disease. Gemcitabine was adapted as the standard of care based on a superior clinical benefit rate in comparison to 5-fluorouracil (5-FU) [2]. Since then, multiple combinations of gemcitabine with other cytotoxic agents such as cisplatin, oxaliplatin and capecitabine have been evaluated with no overall survival benefit [3-5]. Similarly, the combination of gemcitabine with antibodies against the epidermal growth factor receptor (cetuximab) or the vascular endothelial growth factor (bevacizumab) did not result in improved survival [6,7]. Erlotinib, a small molecule inhibitor of the tyrosine kinase domain of epidermal growth factor receptor (EFGR), received FDA approval for the treatment of advanced pancreatic cancer in combination with gemcitabine based on a modest 12 day benefit in overall survival [8].

Sorafenib is a multitargeted kinase inhibitor of vascular endothelial growth factor receptors (VEGFR) 2 and 3, platelet derived growth factor receptor and Raf kinase. The anti-tumor effect of Sorafenib is thought to be mediated through its inhibition of the Ras-Raf-Erk pathway involved in cell proliferation as well as its inhibition of VEGFR2 related angiogenesis [9]. The high frequency of Ras mutation and Ras pathway activation in pancreatic cancer provides a strong rationale for the evaluation of the efficacy of Sorafenib in pancreatic cancer [10-12]. Furthermore, in vitro studies have shown that Sorafenib has pro-apoptotic and anti-proliferative properties in several pancreatic cancer cell lines [13]. The combination of gemcitabine and sorafenib had been evaluated in a phase I study and found that full doses of both agents were well tolerated [14]. We performed a noncomparative randomized phase II study of sorafenib alone and of sorafenib in combination with gemcitabine in patients with advanced pancreatic cancer.

\section{Material and methods}

\section{Study design}

This was a multi-center randomized phase II study of sorafenib alone (Arm A) or gemcitabine in combination with sorafenib (Arm B). The primary endpoint was objective response rate. Secondary endpoints included 6 months overall survival, 3 months progression-free survival, and overall survival. Inclusion criteria included pathologic diagnosis of metastatic pancreatic carcinoma; the presence of measurable disease; age $\geq 18$ 
years; life expectancy greater than 3 months; ECOG performance status $\unlhd$; no prior chemotherapy for metastatic disease; completion of prior adjuvant chemotherapy more than 6 months before study entry; adequate bone marrow function (leukocytes $23,000 / \mu l$, absolute neutrophil count $\geq 1500 / \mu 1$, platelets $\geq 100,000 / \mu$, hemoglobin $\geq 9 \mathrm{~g} / \mathrm{dL}$ ); total bilirubin $\unlhd .5$ institutional upper limit of normal (IULN), aspartate aminotransferase and alanine aminotransferase $3 \times$ IULN in the absence of liver metastases and $5 \times$ XIULN in the presence of liver metastases; creatinine $\triangle .5$ IULN or creatinine clearance $\varangle 0 \mathrm{ml} / \mathrm{min} / 1.73$ $\mathrm{m}^{2}$. Exclusion criteria included prior exposure to gemcitabine; known brain metastases; evidence of bleeding diathesis; therapeutic doses of anticoagulation.

Treatment plan: Patients randomized to arm A received sorafenib $200 \mathrm{mg}$, two tablets PO twice daily continuously. Patients randomized to arm B received gemcitabine $1000 \mathrm{mg} / \mathrm{m}^{2}$ IV at a rate of $10 \mathrm{mg} / \mathrm{m}^{2} / \mathrm{min}$ weekly for 3 out of 4 weeks and sorafenib $200 \mathrm{mg}$, two tablets PO twice daily continuously. One cycle consisted of 28 days. Patients in arm A were allowed to cross-over to arm B upon progression. Treatment continued until disease progression or unacceptable toxicity.

Patient evaluation: pretreatment evaluations were done within 1 week of starting therapy and included history and physical examination, ECOG performance status evaluation, complete blood count (CBC), chemistry panel (CP), urinalysis, and electrocardiogram. Baseline radiologic investigations for staging were performed within 28 days of starting therapy. $\mathrm{CBC}, \mathrm{CP}$ and vital signs including blood pressure evaluation were repeated weekly. Radiologic investigations repeated every 6 weeks and tumor response was assessed based on the Response Evaluation Criteria in Solid Tumors (RECIST) version 1.0. Complete or partial responses required a confirmatory scan at least 4 weeks after initial documentation.

\section{Statistical methods}

This was a randomized non-comparative phase II study of sorafenib alone or sorafenib in combination with gemcitabine. A total of 74 patients were to be randomized to arm A or B (37 per arm). A two stage Simon optimum design was used [15]. In the first stage, accrual was planned to continue until 24 patients (12 per arm) had been assessed for tumor response. If no objective response was noted in 12 patients in either arm, then consideration was given to stop accrual to that arm. In either arm, if at least 4 responses (11\%) of the total of 37 evaluable patients were observed, the regimen would have been regarded worthy of further testing. Otherwise, if 3 or fewer responses out of 37 patients on an arm were observed, further testing of this regimen would not have been warranted. This two-stage design had at least $90 \%$ power to detect a true response rate of at least $20 \%$ in each arm. It yielded at least .90 probability of a negative result if the true response rate were no more than $5 \%$ with at least .54 probability of early negative stopping. With 37 evaluable patients in each arm, the $95 \%$ confidence interval for the response rate in an arm would have a half-width of $\pm 16 \%$ or less.

The study explored the potential additive effects on clinical outcome of the genotypes for all the single nucleotide polymorphisms tested. The association between polymorphisms and progression-free survival and overall survival was examined using Kaplan-Meier plots and $\log$ rank test. In the univariate survival analysis, the Pike estimate of hazard ratio (HR) and its associated $95 \%$ confidence interval $(95 \% \mathrm{CI})$ were based on the log-rank test. No adjustment for multiple comparisons was performed because this study was exploratory in nature and conducted to generate hypotheses for future studies. In addition, a classification and regression tree (CART) method based on recursive partitioning (RP) was used to explore gene polymorphisms for identifying homogeneous subgroups for progression or death. RP analysis is a nonparametric statistical method for modeling a response variable and multiple predictors. RP analysis included all patients in the combination arm of 
gemcitabine and sorafenib with any polymorphism variables available as well as baseline patient characteristics such as gender, race and ECOG performance status. All statistical tests were two-sided. Analyses were performed using the SAS statistical package version 9.1 (SAS Institute Inc. Cary, North Carolina, USA).

\section{Germline polymorphisms analysis}

Polymorphsims in genes involved in gemcitabine metabolism and in angiogenesis pathway were selected for testing to explore any potential predictive or prognostic impact. These included ribonucleotide reductase subunit M1 (RRM1), deoxycytidine deaminase (CDA), Cox-2 and vascular endothelial growth factor (VEGF). We used the following criteria to select genes for study: (i) that the gene be part of a pathway for which there is a credible scientific basis to support its involvement in the gemcitabine metabolism or angiogenesis signaling pathways; (ii) that the gene has an established, well-documented genetic polymorphism; and/or (iii) that the polymorphism has some degree of likelihood to alter the function of the gene in a biologically relevant manner.

Genomic DNA was extracted from peripheral WBC using the QIAamp kit (Qiagen, Valencia, CA, USA). The samples were tested using polymerase chain reaction (PCR) restriction fragment length polymorphism (RFLP) technique. Briefly, forward and reverse primers were used for PCR amplification; PCR products were digested by restriction enzymes (New England Biolab, Ipswich, MA, USA); alleles were separated on 4\% NuSieve ethidium bromide stained agarose gel and/or samples were analyzed by direct sequencing.

\section{Results \\ Patient characteristics}

The study enrolled 52 patients from December 2004 to March 2007; 15 in arm A and 37 in arm B. Accrual to arm A ended after first stage of accrual because no objective responses were noted. Median age was 66 years and 65 years in arms A and B respectively. ECOG performance status was 0 in $40 \%$ and 59\% of patients in arms A and B respectively (Table $1)$.

\section{Treatment}

Arm A: the median number of cycles delivered was 2 (range 1-3). Fourteen out of the 15 patients received a maximum of 2 cycles of Sorafenib alone. Seven patients crossed over upon progression to receive the combination of gemcitabine and sorafenib. The median number of cycles delivered after cross-over was 2 (range 1-14).

Arm B: the median number of cycles delivered was 2 (range 1-11). Seventeen patients $(46 \%)$ received 3 or more cycles of therapy.

\section{Safety}

Arm A: there were no grade 4 toxicities. Seven patients (47\%) experiences grade 3 toxicities. The most common grade 3 toxicities were leucopenia, neutropenia, fatigue, acneiform rash, hand-foot skin reaction, anorexia, AST elevation, alkalaine phosphatase elevation, bilirubin elevation, and sensory neuropathy (7\% each) (Table 2).

Arm B: grade 3 and 4 toxicities occurred in 54\% of patients in arm B. The most common hematologic adverse events were neutropenia $(17 \%)$ and thrombocytopenia $(8 \%)$. The most common grade 3 and 4 non-hematologic toxicities were alkaline phosphatase elevation (14\%), venous thromboembolism (8\%), hypokalemia (5\%), ALT elevation (5\%), and diarrhea (5\%) (Table 2). 


\section{Efficacy}

Arm A: thirteen out of 15 patients were evaluable for response. There were no objective responses. 2 patients had stable disease. Median PFS and OS were 2.3 months (95\% CI: $1.2-$ 5.7) and 4.3 months (95\% CI: 3.3-8.3) respectively; the 3-months PFS probability was 0.36 , and the 6 months survival probability was 0.43 . Two of the 7 patients who crossed over to the combination arm of gemcitabine and sorafenib at the time of progression had stable disease after cross-over lasting 6.1 and 15.8 months respectively (Fig. 1). Two patients were inevaluable for response because of early treatment discontinuation secondary to venous thromboembolism and clinical deterioration (1 patient) and to a cerebrovascular accident (1 patient).

Arm B: Thirty out of 37 patients were evaluable for response. One patient had a partial response and $15(40 \%)$ had stable disease. Median PFS and OS were 2.9 months (95\% CI: 2.1-4.3) and 6.5 months (95\% CI: 5.5-8) respectively; the 3-months PFS probability was 0.45 , and the 6-months survival probability was 0.53 (Fig. 1). Seven patients were inevaluable for response because they completed sone cycle of treatment; reasons for early discontinuation of therapy were patient's choice (2 patients), death secondary rapid disease progression (1 patient), and toxicity (4 patients) including grade 3 fatigue, rash, vomiting related to bowel obstruction, hyponatremia and venous thromboembolism.

\section{Association of gene polymorphisms with outcome}

Single nucleotide polymorphisms in RRM1, CDA, Cox-2 and VEGF were performed on blood samples from 30 patients treated with the combination of gemcitabine and sorafenib. The distribution of the various genotypes and their association with clinical outcome in univariate analysis are listed Table 3. The RRM1 $2464 A / G, R R M 137 C / C$ and $R R M 1524$ $T / T$ alleles were associated with statistically significant superior PFS. The presence of an A allele in the CDA 27 genotype was associated with improved OS. There was no association between polymorphisms in Cox-2 and VEGF and PFS. However, Cox-2 G-765 C and $T 8473 C$ as well as VEGF T-1498 C polymorphisms were associated with OS.

\section{Recursive partitioning analysis of PFS and OS}

For both PFS and OS, RRM1 G2464A polymorphism was the first to separate patients into 2 groups in terms of probability of progression or death. Patients carrying $\mathrm{A} / \mathrm{G}$ of $R R M 1$ $G 2464 A$ had longer PFS and OS compared to those with A/A of RRM1 G2464A. RRM1 T524C and CDA C27A polymorphisms were then noted to further separate patients into different groups for PFS. Compared to the most favorable group of PFS (carrying A/G of $R R M 1 G 2464 A$ ), patients in the least favorable group (carrying A/ A of RRM1 G2464A and C/C of RRM1 T524C) had HR of 7.39 (95\%CI: 1.16-46.94) and PFS of 1.8 months (95\%CI 1.1-2.6). RRM1 A2455G and COX-2 T8473C polymorphisms were picked to split patients into 3 terminal groups for OS. Patients carrying genotype A/A of RRM1 G2464A, A/G or GG of RRM1 A2455G and T/C or C/C of COX-2 T8473C had the highest HR (3.79) and shortest median OS (4.4 months) compared to the most favorable group (carrying $\mathrm{A} / \mathrm{G}$ of RRM1 G2464A) (Fig. 2).

\section{Discussion}

Sorafenib is a multi-targeted tyrosine kinase inhibitor with anti-proliferative and antiangiogenic properties. It has been shown to inhibit Erk 1/2 and STAT3 Tyr705 phosphorylation in pancreatic cancer cell lines. This was accompanied by the suppression of prosurvival Mcl-1 or Bcl-xL proteins, and enhancement of TRAIL -induced apoptosis [17]. Ulivi and colleagues showed similar anti-proliferative effects of sorafenib in pancreatic cell lines independent of the type of KRAS mutation or the activation status of the Ras/Mek/Erk 
pathway [13]. Despite the strong rationale provided by these data, our study revealed no significant activity for sorafenib as a single agent or in combination with gemcitabine. The PFS and OS with the combination were not superior to previous historical results reported with gemcitabine as a single agent [2]. Similarly, the combination of gemcitabine and sorafenib had a PFS of 2.9 months which was identical to the PFS reported with gemcitabine as a single agent in two recently reported randomized phase III studies of gemcitabine in combination with bevacizumab or cetuximab versus gemcitabine alone [6,7]. Our results are consistent with another phase II study of gemcitabine and sorafenib which was discontinued after the first phase of accrual due to the absence of any objective responses, and which revealed a median PFS of 3.2 months and a median OS of 4 months [18]. A recent abstract reported the lack of benefit from the addition of sorafenib to gemcitabine and cisplatin in patients with pancreatic cancer [19].

The lack of efficacy of sorafenib in patients with pancreatic cancer may be due to the significant heterogeneity of pancreatic cancer and its complex biology. It is likely that pancreatic cancer proliferation and progression are dependent on multiple pathways that are redundant and characterized by extensive cross-talk. These pathways may be activated in response to the inhibition of other related pathways, and consequently contribute to the resistance to a specific targeted therapeutic agent, such as sorafenib. Other targeted agents, including cetuximab and bevacizumab, have also failed to improve the efficacy of gemcitabine in patients with advanced pancreatic cancer [6, 7]. In addition, the anti-cancer activity of sorafenib may be dependent to a significant extent on its anti-angiogenic properties through the inhibition of vascular endothelial growth factor pathway; in that context, the failure of sorafenib is reminiscent of the absence of clinical benefit from the addition of bevacizumab to gemcitabine in patients with advanced pancreatic cancer. Lastly, it is possible that gemcitabine may not be the optimal partner for anti-angiogenic drugs given its already modest activity. Recently, the evaluation of combinations that do not include gemcitabine has become a promising area of active investigation. For instance, the combination of 5-FU with irinotecan and oxaliplatin (FOLFIRINOX) was superior to gemcitabine alone with a significant improvement in overall survival [19]. While the toxicity concerns surrounding FOLFIRINOX make it a potentially poor candidate for combining it with a targeted agent, consideration should be given to cytotoxic agents or combinations, other than gemcitabine, to be examined along with targeted agents.

Pancreatic cancer continues to represent a significant therapeutic challenge. Future strategies need to focus on identifying mutations that play a central role in tumor proliferation and survival, as well as in tumor interaction with the microenvironment. Furthermore, the predictive value of preclinical testing needs to be improved with the adoption of models that are more reflective of the human pancreatic cancer heterogeneity and its interaction with the microenvironment [20].

In this study, we explored the potential effect of single nucleotide polymorphisms of genes associated with gemcitabine metabolism and angiogenesis pathway with clinical outcome. Ribonulceotide reductase catalyses the rate limiting step of deoxyribonucleotide formation, a crucially important step in DNA synthesis and repair. The larger subunit of RR, RRM1, is a target of gemcitabine [21]. High expression of RRM1 has been associated with inferior outcome in patients with advanced lung or pancreatic cancer treated with gemcitabine based chemotherapy [22-24]. The RRM1 $2464 G>$ A polymorphism has been noted to predict chemosensitivity to gemcitabine in human pancreatic cancer cell lines when compared with the wildtype RRM1 $2464 G G$ genotype. Furthermore, in oligonucleotide microarray analysis, 69 genes were selected which expressed differently between RRM1 wildtype and the G2464A polymorphism [25]. To our knowledge, our study represents the first report of an association of $R R M 1 G 2464 A$ polymorphism and clinical outcome. The $R R M 1 C-37 A$ 
and RRM1 T524C polymorphisms impact promoter activity. Patients with the RRM1 37CC and $R R M 1524 T T$ genotypes had superior progression-free survival in our study, which is consistent with the improved outcome noted in patients with lung cancer carrying the $R R M 1$ 37CC-RRM1 524TT allelotype [26].

Single nucleotide polymorphisms in genes in the angiogenesis pathway were also found to be associated with outcome. . The Cox-2 $765 C$ variant was associated with shorter OS, possibly due to the role of this variant in enhancing Cox-2 expression and prostaglandin production $[27,28]$. The $C O X-2+8473 T>C$ polymorphism within the functional region of 3 '-untranslated region of the gene may have a potential functional relevance in carcinogenesis, perhaps through control of mRNA-stability and degradation [29]. In our study, the lower expression variant $C O X-28743 C$ was associated with superior OS. The $V E G F-1498 T / T$ genotype was found to be associated with improved OS in our study. The same genotype was associated with a higher disease-control rate in patients with metastatic non-small cell lung cancer treated with sorafenib [30]. The associations observed are limited by the small sample size and the lack of correction for multiple comparisons, and should be considered hypothesis generating observations that require further validation. If validated, the associations of certain polymorphisms with outcome may allow for improved patient selection and therefore superior clinical benefit.

\section{Acknowledgments}

Funding Supported in part by Grants No. NO1 CM-62209, P30CA033572 and P30CA14089 from the National Institutes of Health.

\section{References}

1. Altekruse, SF.; Kosary, CL.; Krapcho, M.; Neyman, N.; Aminou, R.; Waldron, W.; Ruhl, J.; Howlader, N.; Tatalovich, Z.; Cho, H.; Mariotto, A.; Eisner, MP.; Lewis, DR.; Cronin, K.; Chen, HS.; Feuer, EJ.; Stinchcomb, DG.; Edwards, BK. SEER Cancer Statistics Review, 1975-2007, based on November 2009 SEER data submission, posted to the SEER web site. National Cancer Institute; 2010. http://seer.cancer.gov/csr/1975_2007/index.html [Accessed November 18 2010]

2. Burris HA 3rd, Moore MJ, Andersen J, Green MR, Rothenberg ML, Modiano MR, Cripps MC, Portenoy RK, Storniolo AM, Tarassoff P, Nelson R, Dorr FA, Stephens CD, Von Hoff DD. Improvements in survival and clinical benefit with gemcitabine as first-line therapy for patients with advanced pancreas cancer: a randomized trial. J Clin Oncol. 1997; 15(6):2403-2413. [PubMed: 9196156]

3. Colucci G, Labianca R, Di Costanzo F, Gebbia V, Carteni G, Massidda B, Dapretto E, Manzione L, Piazza E, Sannicolo M, Ciaparrone M, Cavanna L, Giuliani F, Maiello E, Testa A, Pederzoli P, Falconi M, Gallo C, Di Maio M, Perrone F. Randomized phase III trial of gemcitabine plus cisplatin compared with single-agent gemcitabine as first-line treatment of patients with advanced pancreatic cancer: the GIP-1 study. J Clin Oncol. 28(10):1645-1651. [PubMed: 20194854]

4. Poplin E, Feng Y, Berlin J, Rothenberg ML, Hochster H, Mitchell E, Alberts S, O'Dwyer P, Haller D, Catalano P, Cella D, Benson AB 3rd. Phase III, randomized study of gemcitabine and oxaliplatin versus gemcitabine (fixed-dose rate infusion) compared with gemcitabine (30-minute infusion) in patients with pancreatic carcinoma E6201: a trial of the Eastern Cooperative Oncology Group. J Clin Oncol. 2009; 27(23):3778-3785. [PubMed: 19581537]

5. Cunningham D, Chau I, Stocken DD, Valle JW, Smith D, Steward W, Harper PG, Dunn J, TudurSmith C, West J, Falk S, Crellin A, Adab F, Thompson J, Leonard P, Ostrowski J, Eatock M, Scheithauer W, Herrmann R, Neoptolemos JP. Phase III randomized comparison of gemcitabine versus gemcitabine plus capecitabine in patients with advanced pancreatic cancer. J Clin Oncol. 2009; 27(33):5513-5518. [PubMed: 19858379]

6. Philip PA, Benedetti J, Corless CL, Wong R, O'Reilly EM, Flynn PJ, Rowland KM, Atkins JN, Mirtsching BC, Rivkin SE, Khorana AA, Goldman B, Fenoglio-Preiser CM, Abbruzzese JL, Blanke CD. Phase III study comparing gemcitabine plus cetuximab versus gemcitabine in patients with 
advanced pancreatic adenocarcinoma: Southwest Oncology Group-directed intergroup trial S0205. J Clin Oncol. 28(22):3605-3610. [PubMed: 20606093]

7. Kindler HL, Niedzwiecki D, Hollis D, Sutherland S, Schrag D, Hurwitz H, Innocenti F, Mulcahy MF, O'Reilly E, Wozniak TF, Picus J, Bhargava P, Mayer RJ, Schilsky RL, Goldberg RM. Gemcitabine plus bevacizumab compared with gemcitabine plus placebo in patients with advanced pancreatic cancer: phase III trial of the Cancer and Leukemia Group B (CALGB 80303). J Clin Oncol. 28(22):3617-3622. [PubMed: 20606091]

8. Moore MJ, Goldstein D, Hamm J, Figer A, Hecht JR, Gallinger S, Au HJ, Murawa P, Walde D, Wolff RA, Campos D, Lim R, Ding K, Clark G, Voskoglou-Nomikos T, Ptasynski M, Parulekar W. Erlotinib plus gemcitabine compared with gemcitabine alone in patients with advanced pancreatic cancer: a phase III trial of the National Cancer Institute of Canada Clinical Trials Group. J Clin Oncol. 2007; 25(15):1960-1966. [PubMed: 17452677]

9. Wilhelm SM, Carter C, Tang L, Wilkie D, McNabola A, Rong H, Chen C, Zhang X, Vincent P, McHugh M, Cao Y, Shujath J, Gawlak S, Eveleigh D, Rowley B, Liu L, Adnane L, Lynch M, Auclair D, Taylor I, Gedrich R, Voznesensky A, Riedl B, Post LE, Bollag G, Trail PA. BAY 439006 exhibits broad spectrum oral antitumor activity and targets theRAF/MEK/ERKpathway and receptor tyrosine kinases involved in tumor progression and angiogenesis. Cancer Res. 2004; 64(19):7099-7109. [PubMed: 15466206]

10. He AR, Lindenberg AP, Marshall JL. Biologic therapies for advanced pancreatic cancer. Expert Rev Anticancer Ther. 2008; 8(8):1331-1338. [PubMed: 18699769]

11. Klimstra DS, Longnecker DS. K-ras mutations in pancreatic ductal proliferative lesions. Am J Pathol. 1994; 145(6):1547-1550. [PubMed: 7992857]

12. Rozenblum E, Schutte M, Goggins M, Hahn SA, Panzer S, Zahurak M, Goodman SN, Sohn TA, Hruban RH, Yeo CJ, Kern SE. Tumor-suppressive pathways in pancreatic carcinoma. Cancer Res. 1997; 57(9):1731-1734. [PubMed: 9135016]

13. Ulivi P, Arienti C, Amadori D, Fabbri F, Carloni S, Tesei A, Vannini I, Silvestrini R, Zoli W. Role of RAF/MEK/ERK pathway, p-STAT-3 and Mcl-1 in sorafenib activity in human pancreatic cancer cell lines. J Cell Physiol. 2009; 220(1):214-221. [PubMed: 19288493]

14. Siu LL, Awada A, Takimoto CH, Piccart M, Schwartz B, Giannaris T, Lathia C, Petrenciuc O, Moore MJ. Phase I trial of sorafenib and gemcitabine in advanced solid tumors with an expanded cohort in advanced pancreatic cancer. Clin Cancer Res. 2006; 12(1):144-151. [PubMed: 16397036]

15. Simon R. Optimal two-stage designs for phase II clinical trials. Control Clin Trials. 1989; 10(1):110. [PubMed: 2702835]

16. Huang S, Sinicrope FA. Sorafenib inhibits STAT3 activation to enhance TRAIL-mediated apoptosis in human pancreatic cancer cells. Mol Cancer Ther. 9(3):742-750. [PubMed: 20197401]

17. Kindler HL, Wroblewski K, Wallace JA, Hall MJ, Locker G, Nattam S, Agamah E, Stadler WM, Vokes EE. Gemcitabine plus sorafenib in patients with advanced pancreatic cancer: a phase II trial of the University of Chicago Phase II Consortium. Invest New Drugs.

18. Kindler HL, Wroblewski K, Wallace JA, Hall MJ, Locker G, Nattam S, Agamah E, Stadler WM, Vokes EE. Gemcitabine plus sorafenib in patients with advanced pancreatic cancer: a phase II trial of the University of Chicago Phase II Consortium. Invest New Drugs.

19. Conroy, T.; Desseigne, F.; Ychou, M.; Ducreux, M.; Bouche, O.; Guimbaud, R.; Becouarn, Y.; Montoto-Grillot, C.; Gourgou-Bourgade, S. Adenis A Randomized phase III trial comparing FOLFIRINOX (F: 5FU/leucovorin [LV], irinotecan [I], and oxaliplatin [O]) versus gemcitabine (G) as first-line treatment for metastatic pancreatic adenocarcinoma (MPA): Preplanned interim analysis results of the PRODIGE 4/ACCORD 11 trial. Abstract \#4010; Proceedings of the American Society of Clinical Oncology; 2010.

20. Philip PA, Mooney M, Jaffe D, Eckhardt G, Moore M, Meropol N, Emens L, O'Reilly E, Korc M, Ellis L, Benedetti J, Rothenberg M, Willett C, Tempero M, Lowy A, Abbruzzese J, Simeone D, Hingorani S, Berlin J, Tepper J. Consensus report of the national cancer institute clinical trials planning meeting on pancreas cancer treatment. J Clin Oncol. 2009; 27(33):5660-5669. [PubMed: 19858397] 
21. Plunkett W, Huang P, Xu YZ, Heinemann V, Grunewald R, Gandhi V. Gemcitabine: metabolism, mechanisms of action, and self-potentiation. Semin Oncol. 1995; 22(4 Suppl 11):3-10. [PubMed: 7481842]

22. Rosell R, Scagliotti G, Danenberg KD, Lord RV, Bepler G, Novello S, Cooc J, Crino L, Sanchez JJ, Taron M, Boni C, De Marinis F, Tonato M, Marangolo M, Gozzelino F, Di Costanzo F, Rinaldi M, Salonga D, Stephens C. Transcripts in pretreatment biopsies from a three-arm randomized trial in metastatic non-small-cell lung cancer. Oncogene. 2003; 22(23):3548-3553. [PubMed: 12789263]

23. Rosell R, Danenberg KD, Alberola V, Bepler G, Sanchez JJ, Camps C, Provencio M, Isla D, Taron M, Diz P, Artal A. Ribonucleotide reductase messenger RNA expression and survival in gemcitabine/cisplatin-treated advanced non-small cell lung cancer patients. Clin Cancer Res. 2004; 10(4):1318-1325. [PubMed: 14977831]

24. Nakahira S, Nakamori S, Tsujie M, Takahashi Y, Okami J, Yoshioka S, Yamasaki M, Marubashi S, Takemasa I, Miyamoto A, Takeda Y, Nagano H, Dono K, Umeshita K, Sakon M, Monden M. Involvement of ribonucleotide reductase M1 subunit overexpression in gemcitabine resistance of human pancreatic cancer. Int J Cancer. 2007; 120(6):1355-1363. [PubMed: 17131328]

25. Kwon WS, Rha SY, Choi YH, Lee JO, Park KH, Jung JJ, Kim TS, Jeung HC, Chung HC. Ribonucleotide reductaseM1 (RRM1) 2464 G>A polymorphism shows an association with gemcitabine chemosensitivity in cancer cell lines. Pharmacogenet Genomics. 2006; 16(6):429_ 438. [PubMed: 16708051]

26. Bepler G, Zheng Z, Gautam A, Sharma S, Cantor A, Sharma A, Cress WD, Kim YC, Rosell R, McBride C, Robinson L, Sommers E, Haura E. Ribonucleotide reductase M1 gene promoter activity, polymorphisms, population frequencies, and clinical relevance. Lung Cancer. 2005; 47(2):183-192. [PubMed: 15639717]

27. Papafili A, Hill MR, Brull DJ, McAnulty RJ, Marshall RP, Humphries SE, Laurent GJ. Common promoter variant in cyclooxygenase-2 represses gene expression: evidence of role in acute-phase inflammatory response. Arterioscler Thromb Vasc Biol. 2002; 22(10):1631-1636. [PubMed: 12377741]

28. Szczeklik W, Sanak M, Szczeklik A. Functional effects and gender association of COX-2 gene polymorphism G-765 C in bronchial asthma. J Allergy Clin Immunol. 2004; 114(2):248-253. [PubMed: 15316498]

29. Hu Z, Miao X, Ma H, Wang X, Tan W, Wei Q, Lin D, Shen H. A common polymorphism in the 3'UTR of cyclooxygenase 2/prostaglandin synthase 2 gene and risk of lung cancer in a Chinese population. Lung Cancer. 2005; 48(1):11-17. [PubMed: 15777967]

30. Zhang W, Lee J, Schiller JH, Carbone DP, Chung CH. H.L. Use of germline polymorphisms in VEGF to predict tumor response and progression-free survival in non-small cell lung cancer (NSCLC) patients treated with sorafenib: Subset pharmacogenetic analysis of Eastern Cooperative Oncology Group (ECOG) trial E2501. Abstract \#7607. Proceedings of The American Society of Clinical Oncology. 2010 


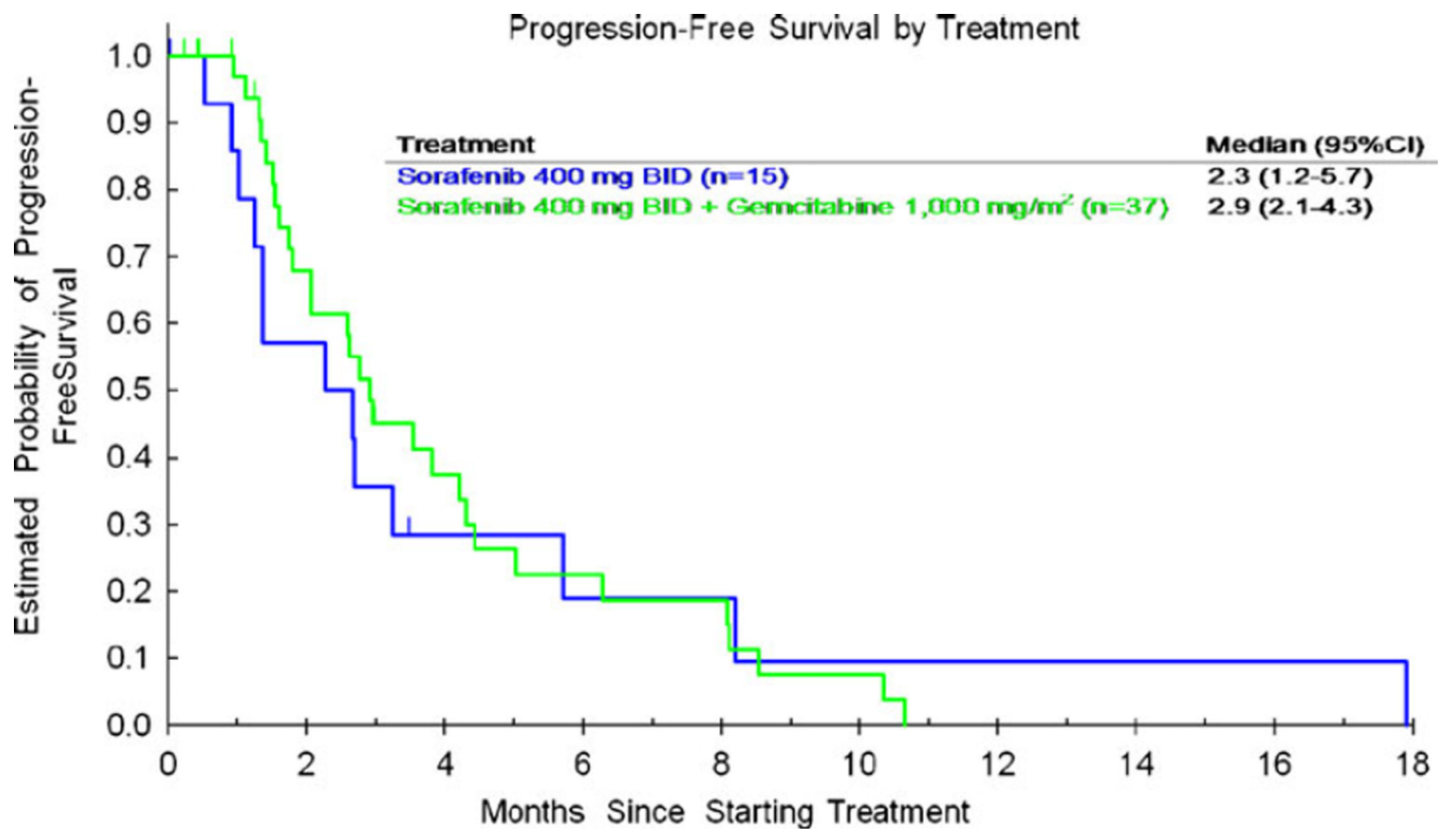

Fig. 1.

PFS for arm A and arm B 


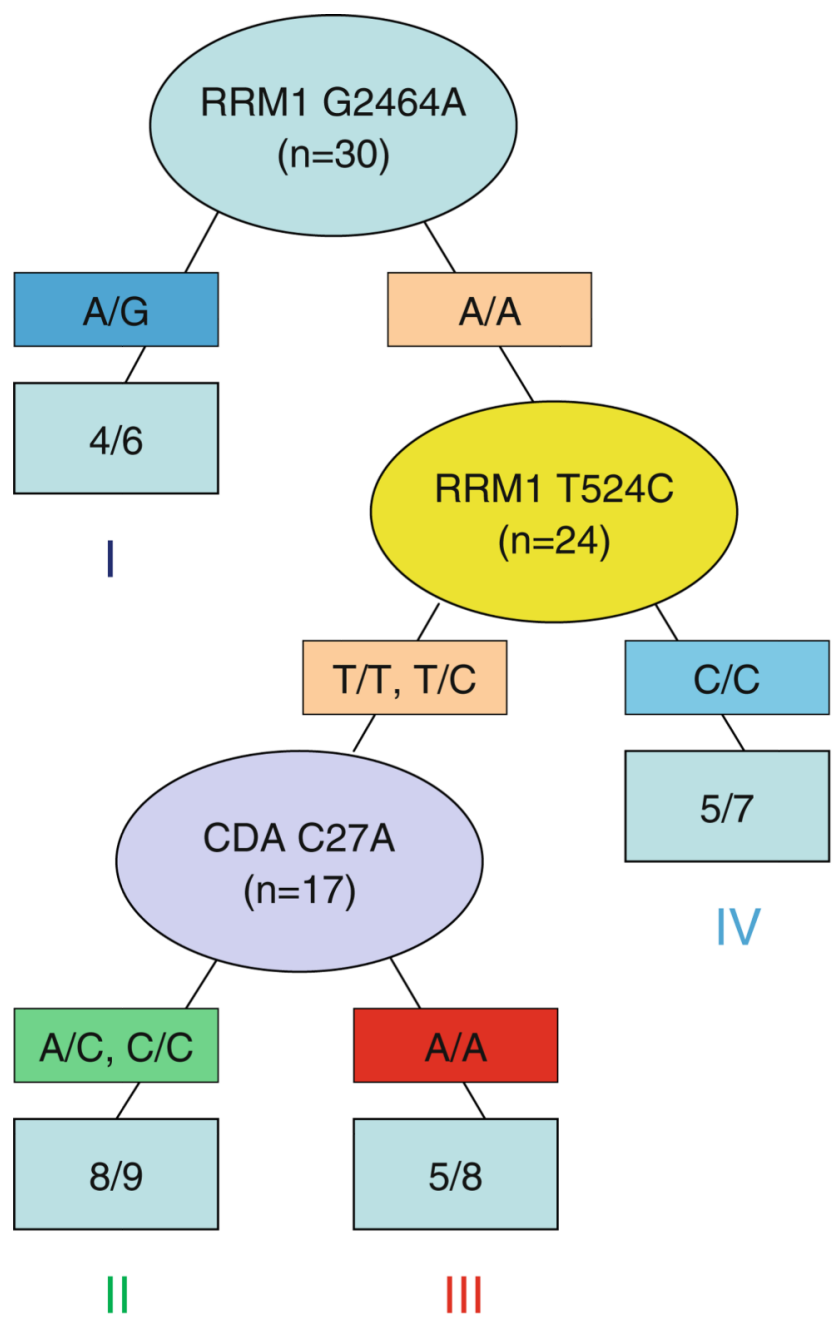

Progression-Free Survival

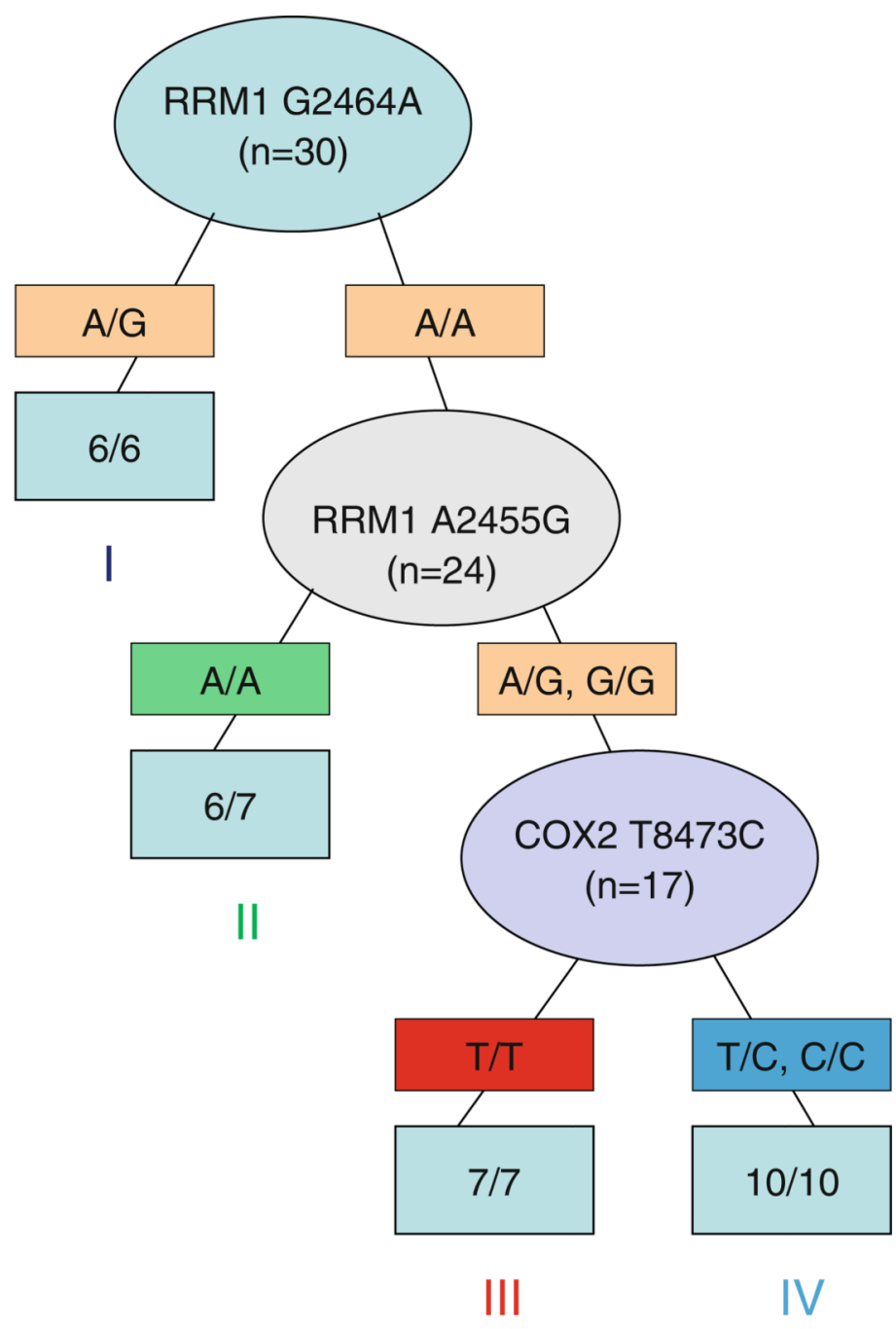

Overall Survival

Fig. 2.

Recursive partitioning analysis: recursive partitioning (RP) was used to explore gene polymorphisms for identifying homogeneous subgroups for progression or death in the gemcitabine and sorafenib arm. In the case of PFS, compared to the most favorable group (carrying A/G of RRM1 G2464A), patients in the least favorable group (carrying A/A of RRM1 G2464A and C/C of RRM1 T524C) had HR of 7.39 (95\% CI: 1.16-46.94) and PFS of 1.8 months (95\%CI 1.1-2.6). In the case of OS, patients carrying genotype A/A of RRM1 G2464A, A/G or GG of RRM1 $A 2455 G$ and T/C or C/C of $C O X-2 T 8473 C$ had the highest HR (3.79) and shortest median OS (4.4 months) compared to the most favorable group (carrying A/G of RRM1 G2464A) 
Table 1

Baseline characteristics

\begin{tabular}{lll}
\hline Characteristics & No. of Patients & \\
\cline { 2 - 3 } & Sorafenib $(\boldsymbol{n}=\mathbf{1 5})$ & Sorafenib+Gemcitabine $(\boldsymbol{n}=\mathbf{3 7})$ \\
\hline Age, y & 66 & 65 \\
Median & $55-82$ & $43-83$ \\
Range & & \\
Sex & $6(40 \%)$ & $15(41 \%)$ \\
Female & $9(60 \%)$ & $22(59 \%)$ \\
Male & & \\
Race & $1(7 \%)$ & $2(5 \%)$ \\
Asian & $0(0 \%)$ & $2(5 \%)$ \\
Black & $12(80 \%)$ & $32(86 \%)$ \\
Caucasian & $2(13 \%)$ & $1(3 \%)$ \\
Hispanic & 0 & $1(3 \%)$ \\
Prior adjuvant or neoadjuvant chemotherapy & $3(8 \%)$ \\
Prior surgery & $1(7 \%)$ & $22(59 \%)$ \\
ECOG Performance Status & & $15(41 \%)$ \\
0 & $6(40 \%)$ & \\
1 & $9(60 \%)$ & \\
\hline
\end{tabular}


Table 2

Grade 3 and 4 adverse events attributed to study drug(s)

\begin{tabular}{|c|c|c|c|c|}
\hline & \multicolumn{4}{|c|}{ No. of Patients (\%) } \\
\hline & \multicolumn{2}{|c|}{ Sorafenib $(n=15)$} & \multicolumn{2}{|c|}{$\underline{\text { Sorafenib+Gemcitabine }(n=37)}$} \\
\hline & Grade 3 & Grade 4 & Grade 3 & Grade 4 \\
\hline \multicolumn{5}{|l|}{ Hematologic Toxicity } \\
\hline Hemoglobin & & & $1(3 \%)$ & \\
\hline Leukocytes (total WBC) & $1(7 \%)$ & & $1(3 \%)$ & \\
\hline Lymphopenia & & & $2(5 \%)$ & \\
\hline Neutrophils/granulocytes (ANC/AGC) & $1(7 \%)$ & & $5(14 \%)$ & $1(3 \%)$ \\
\hline Platelets & & & $2(5 \%)$ & $1(3 \%)$ \\
\hline \multicolumn{5}{|l|}{ Non-Hematologic Toxicity } \\
\hline Thrombotic microangiopathy & & & $1(3 \%)$ & \\
\hline fatigue & $1(7 \%)$ & & $1(3 \%)$ & \\
\hline Rash: acne/acneiform & $1(7 \%)$ & & & \\
\hline Rash: hand-foot skin reaction & $1(7 \%)$ & & $1(3 \%)$ & \\
\hline \multicolumn{5}{|l|}{ Gastrointestinal } \\
\hline Anorexia & $1(7 \%)$ & & & \\
\hline Diarrhea & & & $2(5 \%)$ & \\
\hline Hemorrhage, GI & & & $1(3 \%)$ & \\
\hline \multicolumn{5}{|l|}{ Metabolic/laboratory } \\
\hline ALT & & & $2(5 \%)$ & \\
\hline AST & $1(7 \%)$ & & $1(3 \%)$ & \\
\hline Alkaline phosphatase & $1(7 \%)$ & & $3(14 \%)$ & \\
\hline Bilirubin (hyperbilirubinemia) & $1(7 \%)$ & & & \\
\hline Potassium, serum-low (hypokalemia) & & & $2(5 \%)$ & \\
\hline Sodium, serum-low (hyponatremia) & & & $1(3 \%)$ & \\
\hline \multicolumn{5}{|l|}{ Neurology } \\
\hline CNS cerebrovascular ischemia & $1(7 \%)$ & & & \\
\hline Neuropathy: sensory & $1(7 \%)$ & & $1(3 \%)$ & \\
\hline Pain & & & $1(3 \%)$ & \\
\hline Thrombosis/embolism & & & $2(5 \%)$ & $1(3 \%)$ \\
\hline $\mathrm{N}$ of patients having grade 3 or 4 adverse events & \multicolumn{2}{|c|}{$7(47 \%)$} & \multicolumn{2}{|c|}{$20(54 \%)$} \\
\hline
\end{tabular}




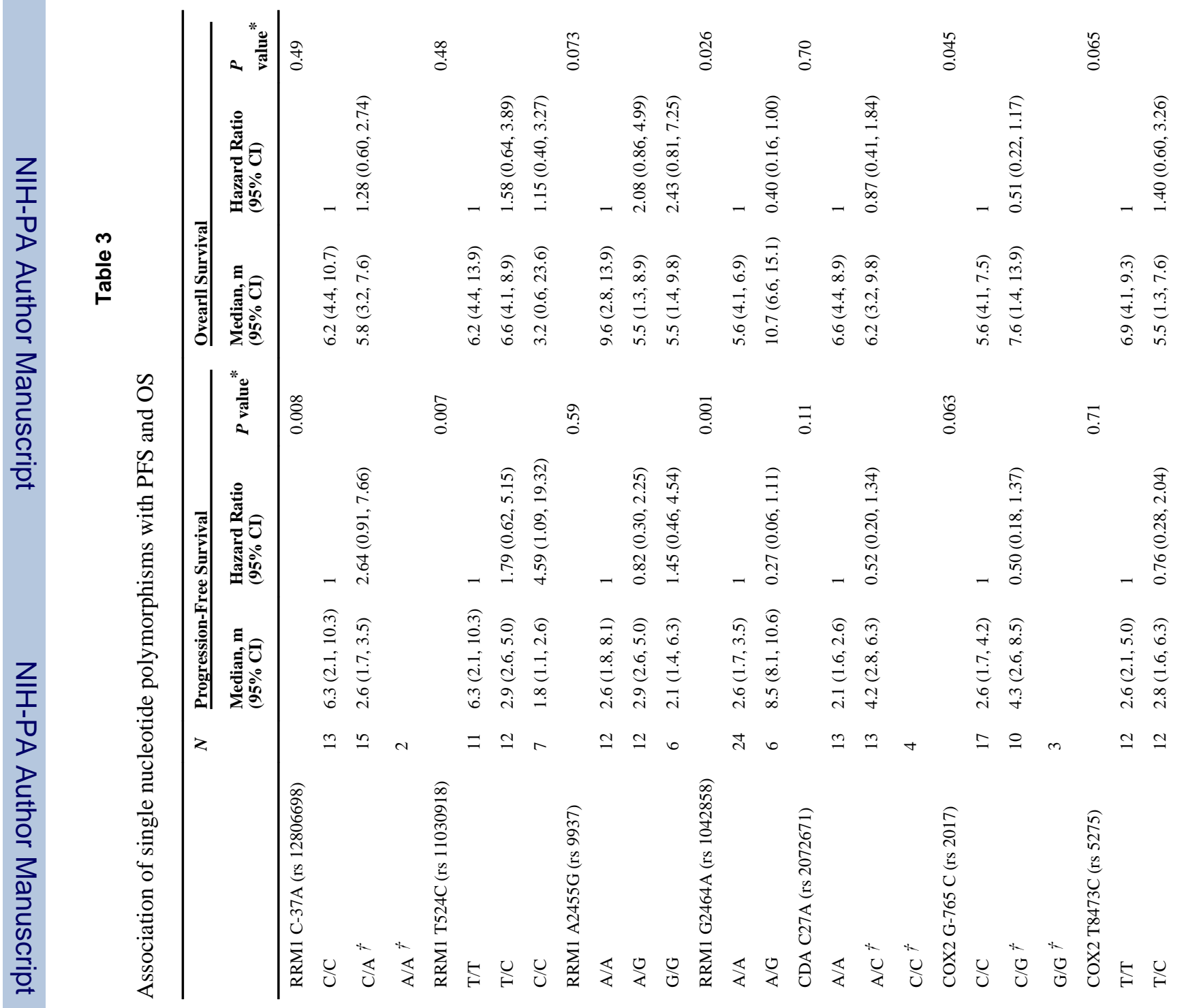




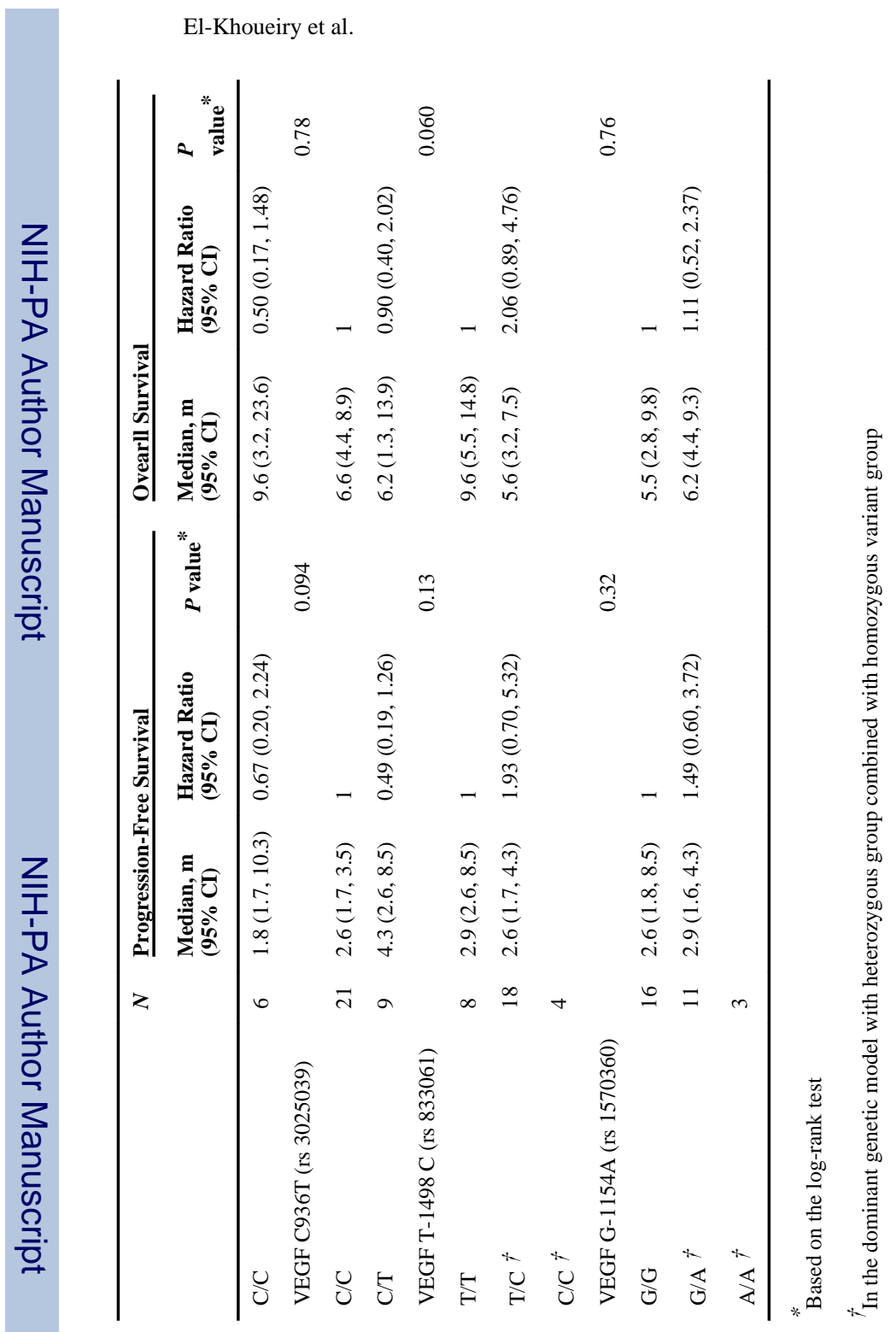

Page 15 